Review Article

\title{
The choice of antihypertensive therapy in the diabetic patient
}

\author{
A.D. Struthers \\ Department of Clinical Pharmacology, Royal Postgraduate Medical School, Ducane Road, London W120HS, UK.
}

\section{Introduction}

Arterial hypertension is common in patients with diabetes mellitus. In Type I diabetes, there is a significant increase in hypertension although, as would be expected, part of this association is due to the presence of diabetic nephropathy (Christlieb et al., 1981). In type II diabetics also, hypertension and diabetes are commonly associated and here obesity is the factor which could produce a spurious association (Barrett-Connor et al., 1981). Despite these possible confounding factors, most studies which have taken obesity and nephropathy into account still report a significant association between hypertension and diabetes, although this remains a controversial point (Drury, 1983).

In any event, a large number of patients with both hypertension and diabetes do exist. These patients have two major risk factors for cardiovascular disease and it is important, therefore, to establish guidelines for their management. Furthermore, we now have information that controlling blood pressure in diabetics is positively beneficial as far as the progression of nephropathy is concerned. Balanced against this, however, is the problem that most available antihypertensive drugs are known to worsen glycaemic control and we have no comparative data to guide us on which drugs we should use. This review will discuss the importance of hypertension in diabetic patients and examine the evidence for and against the use of each drug in these patients.

\section{The importance of blood pressure in diabetic patients}

Three recent observations have focussed attention on the importance of hypertension in diabetic patients.

The large Whitehall study has shown that among glucose intolerant and diabetic subjects, the risk factors most strongly related to subsequent death from coronary heart disease are age and blood pressure,

Correspondence: A.D. Struthers, B.Sc., M.D., M.R.C.P. Accepted: 22 January 1985 with less consistent relationships for other familiar risk factors such as smoking, cholesterol and obesity (Fuller et al., 1983). Whether reducing the blood pressure of hypertensive diabetic patients actually lowers this increased risk of coronary heart disease is another question entirely. It should be remembered that in non-diabetic patients with hypertension, lowering the elevated blood pressure reduces cerebrovascular and overall mortality but has little impact on coronary heart disease mortality per se.

Secondly, in a controlled study of Pima indians with maturity onset diabetes, patients with systolic pressure of $>145 \mathrm{~mm} \mathrm{Hg}$ had a two-fold excess of the development of exudative retinopathy over a $6 y$ period compared with those with systolic pressures $<125 \mathrm{~mm} \mathrm{Hg}$ (Knowler et al., 1980). This interesting observation should, however, be interpreted with caution since it is possible that both hypertension and retinopathy are markers of an underlying microangiopathy. In particular, it should be appreciated that no controlled study has been performed to establish whether antihypertensive treatment has any effect on the natural history of diabetic retinopathy.

The third and most important observation, however, is that in established drabetic nephropathy antihypertensive therapy is able to reduce the rate of decline in both glomerular filtration rate and in the quantity of albuminuria (Parving et al., 1983). This is the only instance in which antihypertensive therapy in diabetics has actually been shown to be positively beneficial with regard to the progression of an established complication. The importance of this observation is highlighted by the fact that such an improvement is not seen with the long term normalization of blood glucose by continuous subcutaneous insulin infusion which has been shown to have little influence on the rate of decline in glomerular filtration rate in patients with established diabetic nephropathy (Viberti et al., 1983). Cynics claim, therefore, that in our diabetic clinics we should be paying more attention to treating blood pressure than blood sugar. This is, of course, an extreme viewpoint but it is likely that 
today's aggressive treatment of blood sugar levels has unmasked hypertension as the next most important factor requiring treatment in diabetic patients.

\section{What level of blood pressure requires treatment?}

There are no large scale epidemiological studies of hypertension in diabetic patients to help us in this matter and we can therefore only be guided by the large scale epidemiological studies of nondiabetic patients with essential hypertension.

The situation is also more complex in patients with hypertension and diabetes. Our threshold for treating blood pressure should probably be reduced in diabetic patients since the co-existence of diabetes confers additional cardiovascular risk. On the other hand, if, as is suggested, the reason for disappointing results in studies such as the Multiple Risk Factor Intervention Trial (MRFIT) in 1982 is that antihypertensive therapy itself produces adverse metabolic effects, then these effects might be even greater in patients with a co-existent metabolic derangement such as diabetes. It would therefore seem a reasonable compromise to suggest that in diabetic patients as in nondiabetic ones, blood pressure be reduced to below a diastolic pressure of $90 \mathrm{~mm} \mathrm{Hg}$. This guideline should naturally be interpreted in a flexible manner for each individual patient and adjusted according to other factors such as age, drug tolerability and coincidental risk factors.

\section{Choice of antihypertensive therapy}

Most antihypertensive drugs produce a number of metabolic effects which are liable to be disadvantageous in diabetics in whom glucose, lipid and intermediary metabolism are already abnormal. This places non-pharmacological methods of reducing blood pressure into particular prominence in diabetic patients. Weight reduction and dietary salt restriction are the main non-pharmacological methods available. Both have been shown in most studies to produce a small but significant reduction in blood pressure at least in patients with essential hypertension (McGregor et al., 1982; Pacy et al., 1984). Weight reduction is obviously of benefit to obese maturity onset diabetics to improve their blood glucose levels irrespective of their blood pressure.

Many studies have been undertaken to assess the effect of antihypertensive drugs on metabolic control in diabetes. There are, however, different ways of studying this problem. One is for a group of diabetic patients to undergo a glucose tolerance test followed by. several weeks of drug therapy after which the glucose tolerance test is repeated. Although the stimulus to insulin release is carefully standardized, it is unphysiological. Instead, overall control is best established in clinical practice by the measurement of HbAIC, and by the repeated home measurements of blood glucose at different times of the day as the patient undergoes his normal life. This latter method should therefore also be used to study the glycaemic effect of various antihypertensive drugs but unfortunately most studies use the former method.

\section{Beta-blockers}

$\boldsymbol{\beta}$-Adrenoceptor antagonists are probably the most commonly used first line drugs in essential hypertension but they have a profound influence on catecholamine mediated metabolic effects (Table I).

The first situation of importance in diabetic patients is hypoglycaemia, especially in insulin dependent diabetics. The restoration of a normal blood glucose level is dependent on increased levels of catecholamines, glucagon and cortisol. These counterregulatory hormones lead to hepatic glycogenolysis and gluconeogenesis, the former of which is limited by the size of the glycogen stores and the latter by the availability of gluconeogenic substrates.

Several studies have compared the effect of different $\beta$-blockers on the blood glucose recovery in insulin induced hypoglycaemia in insulin dependent diabetics (Lager et al., 1979; Deacon et al., 1977). An almost universal finding is that nonselective $\beta$-blockers but not cardioselective $\beta$-blockers delay the blood glucose recovery with some reduction also in the release of gluconeogenetic substates such as lactate. These drugs do not, however, actually influence the absolute minimum level of blood glucose achieved. Neither do they cause any impairment in release of the various counterregulatory hormones. Rather, it is likely that nonselective $\beta$-blockers produce this effect by impairing $\boldsymbol{\beta}_{2}$-mediated glycogenolysis and by reducing the availability of substrates for gluconeogenesis.

Another hazard with nonselective $\beta$-blockade during hypoglycaemia is that the patient's subjective awareness of hypoglycaemia is diminished. Despite this potential problem, Barnett et al. (1980) followed 150 insulin dependent diabetics for 8 months and

Table I Hazards of $\beta$-blockade in diabetics
A. Hypoglycaemia
Delay blood glucose recovery
Reduce subject awareness
Cause a hypertensive response
B. Overall glycaemic control
C. Lipids?
Deteriorates slightly
D. Peripheral vascular effects? 
found that the incidence of hypoglycaemic unconscious episodes was no greater in the $\beta$-blocker treated group than in a control group despite the fact that $86 \%$ of the treated group were taking nonselective $\beta$ blockers.

The final concern is that during hypoglycaemia in the presence of nonselective $\beta$-blockade, increased catecholamines cause increased $\alpha$-receptor stimulation leading to peripheral vasoconstriction and a rise in blood pressure (Lloyd-Mostyn \& Oram, 1975). Such a hypertensive response would be particularly harmful in patients whose initial blood pressures were elevated.

The second main consideration with $\beta$-blockers is their effects on overall glycaemic control. This effect is a result of the involvement of the adrenergic nervous system on the release of insulin from the pancreas. In general, stimulation of $\beta_{2}$-adrenoceptors leads to the release of insulin while stimulation of $\alpha_{2}$-adrenoceptors causes inhibition of insulin release (Holm, 1983). Cerasi et al. (1972) found that the infusion of propranolol caused significant inhibition of the insulin response to glucose in normal subjects. However, not all studies have confirmed this (Hedstrand \& Aberg, 1974) and it remains unclear what contribution, if any, $\boldsymbol{\beta}$-adrenoceptors make in the physiological situation where insulin is released in response to the ingestion of a mixed meal.

Several studies have, however, addressed the crucial question of whether $\beta$-blockade causes a deterioration in glycaemic control in diabetic patients. Wright et al. (1979) studied 20 hypertensive diabetics and gave them propranolol $80 \mathrm{mg}$ b.d., metoprolol $100 \mathrm{mg}$ b.d. or placebo, each for 1 month in a double-blind crossover study. Fasting, pre-lunch and mid-afternoon venous blood samples were taken for measurement of blood glucose and the mean levels were higher after both propranolol $(10.7 \mathrm{mmol} / \mathrm{l})$ and metoprolol $(10.1 \mathrm{nmol} / \mathrm{l})$ than after placebo $(8.9 \mathrm{mmol} / \mathrm{l})$. However, many other studies have used oral or intravenous glucose tolerance tests to assess this aspect of $\beta$-blockade. Two studies suggest that nonselective $\beta$-blockade but not cardioselective $\beta$ blockade cause a deterioration in fasting blood glucose and/or glucose tolerance in diabetics while a third study was unable to confirm this (Holm et al., 1980; Groop et al., 1982; Woods et al., 1980).

A third major area of concern is the deleterious effect that $\beta$-blockers have on plasma lipids. This has been extensively studied in nondiabetic patients where $\beta$-blockade caused increased triglyceride levels and decreased HDL levels (Tanaka et al., 1976; WaalManning \& Simpson, 1977) but not in diabetic patients. In one study, however, oxprenolol had no significant effect on lipids in diabetic subjects (Benfield \& Hunter, 1982).

A final point to consider is that cold peripheries and Raynaud's phenomenon are well known hazards of $\beta$ - blockade. Since diabetics are already more prone to vascular disease care must be taken in prescribing $\beta$ blockers for diabetics. There is, it must be said, no hard evidence for an increased risk of peripheral ischaemia in these circumstances.

Therefore, there are areas of concern in prescribing $\beta$-blockade for diabetics although their effects as regards hypoglycaemic attacks and overall glycaemic control are small. However, most of the harmful effects can be minimized, and possibly negated, if the physician uses cardioselective rather than nonselective $\beta$-blockers in diabetic patients.

\section{Thiazide diuretics}

The main alternatives to $\beta$-blockers for the treatment of essential hypertension are thiazide diuretics. However, it has been appreciated since 1960 that these drugs can cause aggravation of pre-existent diabetes mellitus (Goldner et al., 1960) and, more recently, that they can worsen glucose tolerance in nondiabetic subjects (Amery et al., 1978).

It is important to remember that the degree of thiazide-induced hyperglycaemia is dose related. Most of the detailed studies of this phenomenon in diabetic patients were performed 20 years ago when thiazide diuretics were used in relatively large doses often without any attempt to conserve potassium. Therefore, in short term studies in diabetics, chlorothiazide $1 \mathrm{~g} / \mathrm{d}$ caused the fasting blood glucose to increase by approximately $1.5 \mathrm{mmol} / \mathrm{l}$, benzthiazide $150 \mathrm{mg}$ by around $3 \mathrm{mmol} / \mathrm{l}$ and hydrochlorothiazide $150 \mathrm{mg}$ by around $2 \mathrm{mmol} / 1$ (Shapiro et al., 1961; Runyan, 1962; Chazan \& Boshell, 1965; Goldner et al., 1960). However, in a dose of $25 \mathrm{mg} / \mathrm{d}$, hydrochlorothiazide had no significant effect on the mean blood glucose level (Hicks et al., 1973). Nowadays we tend to use lower doses of thiazide diuretics such as $25 \mathrm{mg} /$ day of hydrochlorothiazide and hence hyperglycaemia may be less of a problem even in diabetics than the original studies of this phenomenon suggested. Furthermore, there is good evidence that thiazide-induced hyperglycaemia is related to the coincidental hypokalaemia (Rapoport \& Hurd, 1964; Rowe et al., 1980) and we would expect therefore that the current trend towards closer maintenance of normal serum potassium levels would reduce the tendency towards hyperglycaemia. However, potassium sparing diuretics do still possess a diabetogenic effect as has been shown in a large study of nondiabetic elderly patients where hydrochlorothiazide $(25 \mathrm{mg})$ plus triamterene $(50 \mathrm{mg})$ caused a significant increase in fasting glucose after 2 y (Amery et al., 1978).

The dangers of hyperkalaemia must also be borne in mind when diabetic patients are treated with potassium sparing diuretics especially in those with auton- 
omic neuropathy or renal failure in whom plasma renin is suppressed (Large et al., 1984). The glycaemic effect of potassium sparing diuretics has also not been adequately assessed in diabetic subjects and the degree of glycaemia which potassium sparing diuretics cause in diabetic patients remains unknown. In particular, we would want to know how this relates to the small glycaemic effect of cardioselective $\beta$-blockers in these patients. In the absence of this information it would seem likely, judging from their relative effects in nondiabetic subjects, that the cardioselective $\beta$-blockers would have a lesser hyperglycaemic effect than potassium sparing diuretics. Therefore, cardioselective $\beta$-blockers would seem the best first line drug for use in hypertensive diabetic subjects although it should be appreciated that this advice is formulated on a less than firm basis.

As with $\beta$-blockers, thiazide diuretics are also known to have a deleterious effect on plasma lipids. In general, thiazide diuretics increase LDL cholesterol, total cholesterol and triglyceride levels (Perez-Stable \& Caralis, 1983). Although such changes may be particularly relevant in diabetic patients, this has not been adequately studied.

It should also be remembered that thiazide diuretics are associated with a significant incidence of impotence in nondiabetic patients and this problem is liable to be more common in diabetic subjects (MRC Working Party, 1981).

\section{Calcium antagonists}

Calcium antagonists are being used increasingly in the treatment of hypertension. There are theoretical reasons for being especially concerned about their effects in diabetic subjects. This stems from the fact that in perfused islets glucose-induced insulin release is accompanied by changes in calcium flux and membrane potential which can be suppressed by methoxyverapamil (Malaisse et al., 1973). In vitro studies have consistently shown inhibition of insulin release by nifedipine, diltiazem and verapamil (Yamaguchi et al., 1977; Devis et al., 1975). However, it has proven difficult to reproduce these inhibitory effects in vivo. For example, Yamaguchi et al. (1979) found a marked inhibitory effect of diltiazem in rat islets in vitro but no corresponding inhibition of insulin release in conscious rats.

Many studies have been undertaken of the short term effect of these drugs on glucose tolerance and insulin release in both normal subjects and diabetic subjects with conflicting results. In normal subjects, two studies suggest a diabetogenic effect while three other studies found no effect (Charles et al., 1981; de Marinis \& Barbarino, 1980; Joffe et al., 1983; Semple et al., 1983; Donnelly \& Harrower, 1980). The situa- tion is just as confusing in patients with pre-existing diabetes. Guigliano et al. (1980) found that nifedipine $30 \mathrm{mg} / \mathrm{d}$ for $10 \mathrm{~d}$ caused a reduction of both glucose tolerance and insulin secretion in a group of patients with impaired glucose tolerance. In contrast, in other studies the same dose of nifedipine given for 1 month (Donnelly \& Harrower, 1980) and for 3 months (Abadie \& Passa, 1984) had no significant effect on glucose tolerance in patients with non-insulin dependent diabetes. There is even one report in which verapamil was found to improve glucose tolerance in non-insulin dependent diabetics (Rojdmark \& Andersson, 1981). The factors responsible for these discrepancies are unclear but there may be interindividual variation in susceptibility to the diabetogenic effects of these drugs (Bhatnagar et al., 1984). In general, however, the effect of calcium antagonists on glucose tolerance appear to be either small or nonexistent in the majority of diabetic patients. More studies are, however, required to examine the longer term effects of these drugs and especially their effects on overall glycaemic control as assessed by serial blood glucose measurements, rather than simply their short term effects on glucose tolerance.

\section{Vasodilators}

Hydralazine is a commonly used third line drug in the management of hypertension. However, its effects on glycaemic control in diabetic subjects have never been formally assessed. All that can be said is that hydralazine does not affect glucose tolerance in normal subjects (Riley, 1980).

Prazosin is an $\alpha$-adrenoceptor antagonist which also ultimately causes vasodilatation. Insulin release is partly mediated in certain experimental situations by inhibitory $\alpha$-adrenoceptors (Holm, 1983). These are thought to be of the $\alpha_{2}$ subtype (Nakadate et al. 1980) and should not be influenced by doses of prazosin which maintain their $\alpha_{1}$ selectivity. A single dose of prazosin $(2 \mathrm{mg})$ has, however, been found to increase plasma glucose in patients with chemical diabetes (Barbieri et al., 1980a). In contrast, chronic therapy ( $3 \mathrm{mg} /$ day) for 1 week significantly improved glucose tolerance with a slight increase in insulin levels in another group of diabetic patients (Barbieri et al., $1980 \mathrm{~b})$. If this latter observation is confirmed, prazosin could become the drug of choice for diabetic subjects.

Angiotensin converting enzyme (ACE) inhibitors are promising new drugs in the management of hypertension. In addition, there is no reason to believe that ACE inhibitors should influence glucose tolerance in diabetics. The first study on this matter has, however, shown a non-significant increase in blood glucose from $8.4 \pm 1.0 \mathrm{mmol} / 1$ to 
$9.8 \pm 1.1 \mathrm{nmol} / \mathrm{l}$ after captopril and a non-significant increase in the $\mathrm{M}$ value from $12.2 \pm 1.9$ to $25.6 \pm 17.3$ (Sullivan et al., 1984). Further data is required about this and in particular to assess the effect of diuretic/ ACE inhibitor combinations since this is a common and powerful hypotensive regime.

\section{Centrally acting antihypertensive drugs}

These drugs are less frequently used nowadays in the UK but they are still in common use in other parts of the world. Benfield \& Hunter (1982) studied methyldopa in 10 insulin dependent diabetics and found a non-significant increase in fasting blood sugar from $9.8 \pm 1.8 \mathrm{mmol} / 1$ to $12.2 \pm 2.4 \mathrm{mmol} / \mathrm{l}$. Furthermore, in this study, methyldopa produced a small but significant increase in triglycerides, although no changes were seen in high density lipoprotein (HDL) or cholesterol. These changes are cause for concern but it is really in non-insulin dependent diabetics that we principally use methyldopa and where we require more data. Two further considerations with methyldopa relate to its side effect profile, in particular postural hypotension and sexual difficulties as these findings are relatively common in diabetics.

Clonidine is another centrally acting drug which is an $\alpha$-adrenoceptor agonist. Interestingly, Guthrie et al. (1983) have reported that $0.2 \mathrm{mg}$ clonidine per day given for 10 weeks actually decreased glucose tolerance during an intravenous glucose tolerance test in 10 patients with maturity onset diabetes but caused no significant effect on glycaemic control as assessed by weekly fasting plasma glucose, glycosylated haemoglobin and $24 \mathrm{~h}$ urinary glucose excretion.

\section{Conclusions}

Hypertension is rapidly emerging as a factor of extreme importance in diabetic patients, not only as an indicator of increased risk of mortality but also as a contributory factor in the development of diabetic complications. Therefore the diabetic physician must not be content just to achieve euglycaemia in his patients but he must also strive to reduce other risk factors and in particular hypertension. Balanced, however, against this, there is great uncertainty about which drugs should be used.

From the previous discussion it can be seen that the information we have about each drug in diabetes is rather limited and in some cases, conflicting (Table II). Most antihypertensive drugs do worsen glycaemic control in diabetic patients but all to a relatively small extent at least in the majority of patients. In addition, there has been little attempt to compare different antihypertensive drugs within a group of diabetic patients so that we can gauge the relative glycaemic effect of each drug.

In essential hypertension without diabetes, $\beta$-blockers and thiazide diuretics have deservedly gained first equal place in therapy. This is based mainly on the fact that they are especially free of side effects. Therefore, although prazosin and ACE inhibitors look promising for the treatment of hypertensive diabetic patients, more information is required before their use in diabetic patients can be specifically recommended. There is as yet no compelling data about these new drugs to make us depart from the traditional thiazide/ $\beta$-blocker regimes in use for essential hypertension but opinion is unlikely to remain static on this issue.

Table II Degree of deterioration in glycaemic control caused by antihypertensive drugs

$\begin{array}{ll}\text { Beta adrenoceptor antagonists } & \\ \quad \text { Non selective } & - \\ \quad \text { Cardioselective } & - \\ \text { Thiazide diuretics } & \\ \quad \text { Potassium losing } & --- \\ \quad \text { Potassium sparing } & -- \\ \text { Calcium antagonists } & - \\ \text { Hydralazine } & ? \\ \text { Prazosin } & + \\ \text { Centrally acting drugs } & - \\ \text { Converting enzyme inhibitors } & 0\end{array}$

$(+)$ represents improved glucose tolerance; $(-)$ represents deteriorated glucose tolerance; $(0)$ represents unchanged glucose tolerance.

In the meantime, cardioselective $\beta$-blockers are an acceptable first line drug in most hypertensive diabetic patients whether they are insulin treated or not. If this fails, a reasonable second line choice of therapy would be a potassium sparing diuretic in the case of insulin dependent patients without nephropathy or prazosin or other vasodilators in the case of non-insulin dependent diabetics. We must however be aware that many of these drugs, either on their own or in combination will worsen overall glycaemic control albeit to a small extent. Currently, therefore, the main recommendation must be not to use any particular drug but rather that after the institution of any antihypertensive therapy in a diabetic, each patient should be reassessed not only for side effects but also for the biochemical indices of blood glucose, potassium and lipids. Consequent upon this reassessment, their antihypertensive therapy may need to be changed or antidiabetic treatment increased to compensate. In the meantime, we urgently require double-blind 
crossover comparison studies of the various drugs so that our initial choice of therapy can be made on a more rational basis and not, as is required now, by trial and error in each individual patient.

\section{References}

ABADIE, E. \& PASSA, P.M. (1984). Diabetogenic effects of nifedipine. British Medical Journal, 289, 438.

AMERY, A., BULPITT, C., DE SCHAEPDRYVER, A., FAGARD, R., HELLEMANS, J., MUTSERS, A., BERTHAUX, P., DERUYTTERE, M., DOLLERY, C., FORETTE, F., LUNDJOHANSEN, P. \& TUOMILEHTO, J. (1978). Glucose intolerance during diuretic therapy. Results of trial by the European Working Party on Hypertension in the Elderly. Lancet, i, 681.

BARBIERI, C., CALDARA, R., FERRARI, C., DAL BO, G., PARACCHI, A., TOMUSSI, M. \& CURTARELLI, G. (1980a). Metabolic effects of prazosin. Clinical Pharmacology and Therapeutics, 27, 313.

BARBIERI, C., FERRARI, C., BORZIO, M., PIEPOLI, V. \& ClADARA, R. (1980b). Metabolic effects of chronic prazosin treatment. Hormone and Metabolic Research, 12, 331.

BARNETT, A.H., LESLIE, D. \& WATKINS, P.J. (1980). Can insulin-treated diabetics be given beta adrenergic blocking drugs? British Medical Journal, 280, 976.

BARRETT-CONNOR, E., CRIQUI M.H., KLAUBER, M.R. \& HOLDBROOK, M. (1981). Diabetes and hypertension in a community of older adults. American Journal of Epidemiology, 113, 276.

BENFIELD, G.F.A. \& HUNTER, K.R. (1982). Oxprenolol, methyldopa and lipids in diabetes mellitus. British Journal of Clinical Pharmacology, 13, 219.

BHATNAGAR, S.K., AMIN, M.A.A. \& AL-YUSUF. (1984). Diabetogenic effects of nifedipine. British Medical Journal, 289, 19.

CERASI, E., LUFT, R. \& EFENDIC, S. (1972). Effect of adrenergic blocking agents on insulin response to glucose infusion in man. Acta Endocrinologica, 69, 335.

CHARLES, S., KETELSLEGERS, J.M., BUYSSCHAERT, M. \& LAMBERT, A.E. (1981). Hyperglycaemic effect of nifedipine. British Medical Journal, 283, 19.

CHAZAN, J.A. \& BOSHELL, B.R. (1965). Etiological factors in thiazide-induced or aggravated diabetes mellitus. Diabetes, 14, 132.

CHRISTLIEB, A.R., WARRAM, J.H., KROLEWSKI, A.S., BUSICK, E.J., GANDA, O.M., ASMAL, A.C., SOELDNER, J.S. \& BRADLEY, R.F. (1981). Hypertension: the major risk factor in juvenile onset insulin dependent diabetics. Diabetes, 30 (suppl 2), 90.

DEACON, S.P., KARUNAMAYAKE, A. \& BARNETT, D. (1977). Acebutolol, atenolol and propranolol and metabolic responses to acute hypoglycaemia in diabetics. British Medical Journal, 274, 1255.

DE MARINIS, L. \& BARBARINO, A. (1980). Calcium antagonists and hormone release I. Effects of verapamil on insulin release in normal subjects and patients with islet cell tumours. Metabolism, 29, 599.

DEVIS, G., SOMERS, G., VAN OBBERGHEN, E. \& MALAISSE, W.J. (1975). Calcium antagonists and islet function $I$.

\section{Acknowledgement}

I would like to thank Professor S.R. Bloom for helpful comments during the preparation of this manuscript.

Inhibition of verapamil. Diabetes, 24, 547.

DOLLERY, C.T., PENTECOST, B.L. \& SAMAAN, N.A. (1962). Drug induced diabetes. Lancet, ii, 735.

DONNELLY, T. \& HARROWER, A.D.B. (1979). Effect of nifedipine on glucose tolerance and insulin secretion in diabetic and nondiabetic patients. Current Medical Research and Opinion, 6, 690.

DRURY, P.L. (1983). Diabetes and arterial hypertension. Diabetologia, 24, 1.

FULLER, J.H., SHIPLEY, M.J., ROSE, G., JARRETT, R.J. \& KEEN, H. (1983). Mortality from coronary heart disease and stroke in relation to degree of glycaemia: the Whitehall study. British Medical Journal, 287, 867.

GOLDNER, M.G., ZAROWIRZ, H. \& AKGUN, S. (1960). Hyperglycaemia and glycosuria due to thiazide derivatives administered in diabetes mellitus. New England Journal of Medicine, 262, 403.

GROOP, L., TOTTEMAN, K-J, HAMO, K. \& GORDIN, A. (1982). Influence of beta blocking drugs on glucose metabolism in patients with noninsulin dependent diabetes mellitus. Acta Medica Scandinavica, 211, 7.

GUIGLIANO, D., TORELLA, R., CACCIAPUOTI, F., GENTILE, S., VERZA, M. \& VARRICHIO, M. (1980). Impairment of insulin secretion in many by nifedipine. European Journal of Clinical Pharmacology, 18, 395.

GUTHRIE, G.P., MILLER, R.E., KOTCHEN, T.A. \& KOERIG, S.H. (1983). Clonidine in patients with diabetes and mild hypertension. Clinical Pharmacology and Therapeutics, 34, 713.

HEDSTRAND, H. \& ABERG, M. (1974). Insulin response to intravenous glucose during long term treatment with propranolol. Acta Medica Scandinavica, 196, 39.

HICKS, B.H., WARD, J.D., JARRETT, R.J., KEEN, H. \& WISE, P. (1973). A controlled study of clopamide, clorexolone and hydrochlorothiazide in diabetics. Metabolism, 12, 101.

HOLM, G. (1983). Adrenergic regulation of insulin release. Acta Medica Scandinavica, 672, (suppl.), 21

HOLM, G., JOHANSSON, S., VEDIN, A., WILHELMSSON, C. \& SMITH, U. (1980). The effect of beta blockade on glucose tolerance and insulin release in adult diabetics. Acta Medica Scandinavica, 208, 187.

JOFFE, B.I., LAMPREY, J.M., SHIRES, R., BAKER, S., VILJOEN, M. \& SEFTER, H.C. (1983). Lack of hormone effects of a single dose of nifedipine in healthy young men. Journal of Cardiovascular Pharmacology, 5, 700.

KNOWLER, W.C., BENNETT, P.H. \& BALLINTINE, E.J. (1980). Increased incidence of retinopathy in diabetics with elevated blood pressure. New England Journal of Medicine, $302,645$.

LAGER, I., BHOHME, G. \& SMITH, U. (1979). Effect of cardioselective and nonselective $\beta$ blockade on the hypoglycaemic response in insulin dependent diabetics. Lancet, $\mathrm{i}, 458$.

LARGE, D.M., CARR, P.H., LAING, I. \& DAVIES, M. (1984). 
Hyperkalaemia in diabetes mellitus - potential hazards of coexisting hyporeninaemic hypoaldosteronism. Postgraduate Medical Journal, 60, 370.

LLOYD-MOSTYN, R.M. \& ORAM, S. (1975). Modification by propranolol of cardiovascular effects of induced hypoglycaemia. Lancet, i, 1213.

MALAISSE, W., BRISSAN, G.R. \& BAIRD, L.E. (1973). Stimulus-secretion coupling of glucose induced insulin release. X. Effect of glucose on ${ }^{45} \mathrm{Ca}$ efflux from perfused islets. American Journal of Physiology, 224, 389.

MCGREGOR, G.A., MARKANDU, N.D., BEST, F.E., ELDER, D.M., CARN, J.M., SAGNELLA, G.A. \& SQUIRES, M. (1982). Double blind randomised crossover trial of moderate sodium restriction in essential hypertension. Lancet, $\mathbf{i}, 351$.

MEDICAL RESEARCH COUNCIL WORKING PARTY. (1981). Adverse reactions to bendrofluazide and propranolol for the treatment of mild hypertension. Lancet, ii, 539.

MULTIPLE RISK FACTOR INTERVENTION TRIAL. (1982). Risk factor changes and mortality results. Journal of the American Medical Assocation, 248, 1465.

NAKADATE, T., NAKAKI, T., MURAKI, T. \& KATO, R. (1980). Regulation of plasma insulin level by $\alpha_{2}$ adrenergic receptors. European Journal of Pharmacology, 65, 421.

PACY, P., DODSON, P., KUBICKI, A., FLETCHER, R. \& TAYLOR, K. (1984). Effect of a high fibre, high carbohydrate dietary regimen on serum lipids and lipoproteins in type II hypertensive diabetic patients. Diabetics $R e$ search, 1, 159.

PARVING, H.H., ANDERSEN, A.R., SMIDT, U.M. \& SVENDSEN, P.A. (1983). Early aggressive antihypertensive treatment reduces rate of decline in kidney function in diabetic nephropathy. Lancet, i, 1175.

PEREZ-STABLE, E. \& CARALIS, P.V. (1983). Thiazide induced disturbances in carbohydrate, lipid and potassium metabolism. American Heart Journal, 106, 245.

RAPOPORT, M.I. \& HURD, M.F. (1964). Thiazide induced glucose tolerance treated with potassium. Archives of Internal Medicine, 113, 405.

RILEY, A.J. (1980). Some further evidence for partial agonist activity of labetalol. British Journal of Clinical Pharmacology, 9, 517.

ROJDMARK, S. \& ANDERSSON, D.E.M. (1981). Influence of verapamil on glucose tolerance. Acta Medica Scandinavica, 210, 27.

ROWE, J.W., TOBIN, J.D., ROSA, R.M. \& ANDRES, R. (1980).
Effect of experimental potassium deficiency on glucose and insulin metabolism.. Metabolism, 29, 498.

RUNYAN, J.W. (1962). Influence of thiazide diuretics on carbohydrate metabolism in patients with mild diabetes. New England Journal of Medicine, 267, 541.

SEMPLE, C.G., THOMSON, J.A., BEASTALL, G.H. \& LORIMER, A.R. (1983). Oral verapamil does not affect glucose tolerance in non-diabetics. British Journal of Clinical Pharmacology, 15, 570.

SHAPIRO, A.P., BENEDEK, T.G. \& SMALL, J.L. (1961). Effect of thiazides on carbohydrate metabolism in patients with hypertension. New England Journal of Medicine, 265, 1028.

SULLIVAN, P.A., KELLEHER, M., TWORNEY, M. \& DINEEN, M. (1984). Effects of captopril on blood pressure and plasma aldosterone in hypertensive diabetics compared to patients with essential hypertension. Hypertension, (suppl.) (in press).

TANAKA, N., SAKAGUCHI, S., OSHIGE, K., NIIMURA, T.A. \& KANEHISA, T. (1976). Effect of chronic administration of propranolol on lipoprotein composition. Metabolism, 25, 1071.

VIBERTI, G.C., BILOUS, R.W., MACKINTOSH, D., BENDING, J.J. \& KEEN, H. (1983). Long term correction of hyperglycaemia and progression of renal failure in insulin dependent diabetics. British Medical Journal, 286, 598.

WAAL-MANNING, J.J. \& SIMPSON, F.O. (1977). Beta blockers and lipid metabolism. British Medical Journal, 2, 705.

WOODS, K.L., WRIGHT, A.D., KENDALL, M.J. \& BLACK, E. (1980). Lack of effect of propranolol and metoprolol on glucose tolerance in maturity onset diabetics. British Medical Journal, 281, 1321.

WRIGHT, A.D., BARBER, S.G., KENDALL, M.J. \& POOLE, P.H. (1979). Beta adrenoceptor blocking drugs and blood sugar control in diabetes mellitus. British Medical Journal, $1,159$.

YAMAGUCHI, I., AKIMOTO, Y., NAKAJIMA, H. \& KIYOMOTO, A. (1977). Effect of diltiazem on insulin secretion. I. Experiments in vitro. Japanese Journal of Pharmacology, 27, 679.

YAMAGUCHI, I., AKIMOTO, Y., NAKAJIMA, H. \& KIYOMOTO, A. (1979). Effect of diltiazem on insulin secretion. II. Experiments on perfused rat pancreas, anaesthetised dogs and conscious rats. Japanese Journal of Pharmacology, 29, 375. 